
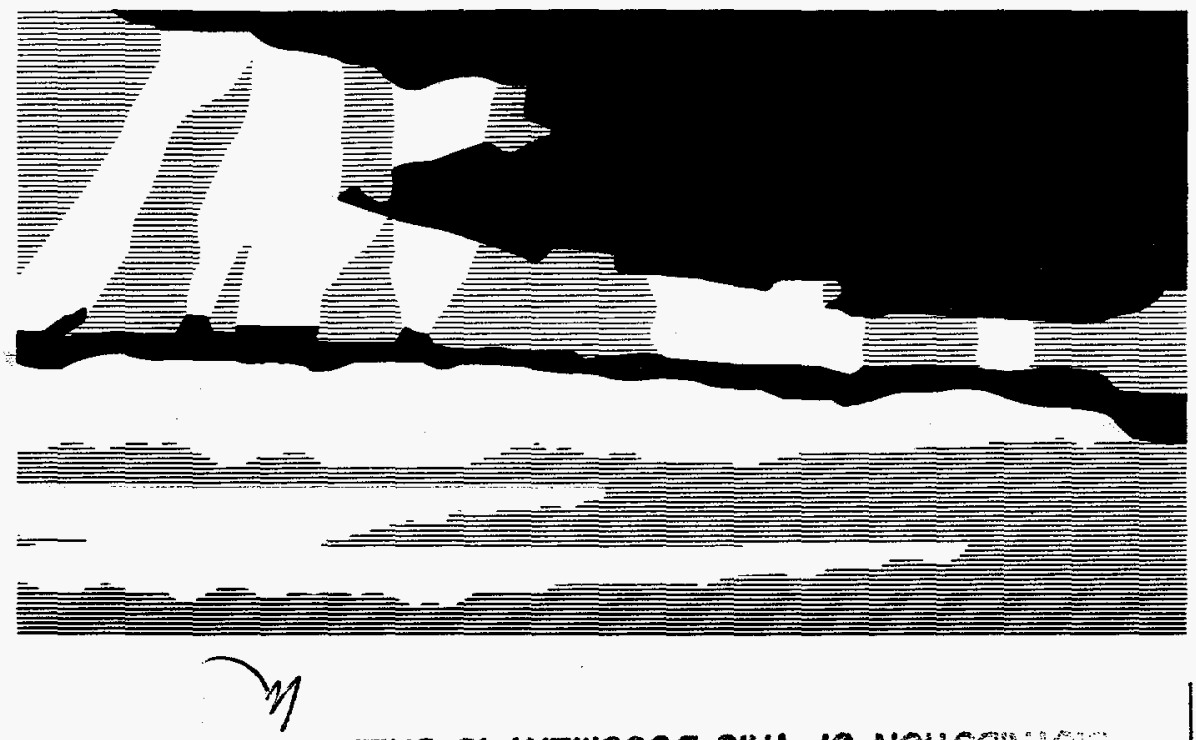

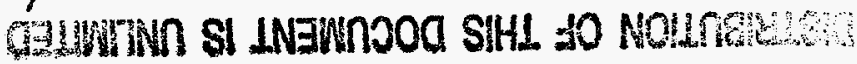

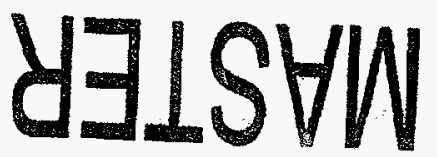

$966+$ ' 6 L-gL llud $\forall$

eu!uo 'bu!neg

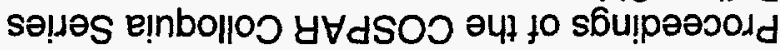

:01 pon!wans

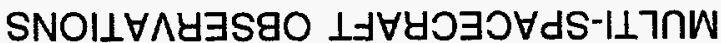

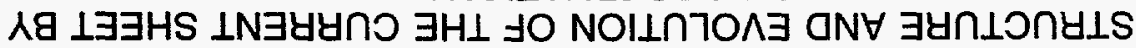

bu!nsog it

\|əssny $17 \cdot 0$

nou $Z \cdot \lambda-x$

:(s)Jount

- -9eetio96-JNog

$2.8-26-7 n-\forall 7$ 


\section{DISCLAIMER}

This report was prepared as an account of work sponsored by an agency of the United States Government. Neither the United States Government nor any agency thereof, nor any of their employees, makes any warranty, express or implied, or assumes any legal liability or responsibility for the accuracy, completeness, or usefulness of any information, apparatus, product, or process disclosed, or represents that its use would not infringe privately owned rights. Reference herein to any specific commercial product, process, or service by trade name, trademark, manufacturer, or otherwise does not necessarily constitute or imply its endorsement, recommendation, or favoring by the United States Government or any agency thereof. The views and opinions of authors expressed herein do not necessarily state or reflect those of the United States Government or any agency thereof. 


\section{DISCLAIMERR}

Portions of this docament mory be illegible in electronic iroge produets. Images are produced from the best arailable original document 


\title{
STRUCTURE AND EVOLUTION OF THE CURRENT SHEET BY MULTI-SPACECRAFT OBSERVATIONS
}

\author{
X.-Y. Zhou ${ }^{1}$, C. T. Russell ${ }^{2}$, and J. Gosling ${ }^{3}$ \\ ${ }^{I}$ Institute of Geophysics, The Chinese Academy of Sciences, Beijing 100101, P.R. China \\ ${ }^{2}$ Institute of Geophysics and Planetary Physics, University of California, Los Angeles, CA 90095, USA \\ ${ }^{3}$ Los Alamos National Laboratory, Los Alamos, NM 87545, USA
}

\begin{abstract}
On April 22, 1979, from 0840 to 1018 UT, ISEE 1, ISEE 2 and IMP 8 were all in or near the magnetotail current sheet at $17 \mathrm{Re}, 16 \mathrm{Re}$ and $35 \mathrm{Re}$ respectively while ISEE 3 monitored the solar wind $206 \mathrm{Re}$ upstream of the Earth. A global perspective of the four spacecraft observations and of the ground magnetic records is presented in this paper. The hyperbolic tangent current sheet model of Harris has been used to calculate the current sheet thickness and to analyze the plasma distribution in the vertical direction. It is found that during this event the current sheet thickness varied from $2.5 \operatorname{Re}$ to $1.5 \operatorname{Re}$ for northward IMF but thinned abruptly to 0.5 Re when the IMF turned southward.
\end{abstract}

\section{INTRODUCTION}

The plasma and current sheets in the geomagnetic tail are the critical regions in both the coupling of the magnetosphere to the solar wind and the storage of energy for later release. The properties and evolution of these layers are intimately involved in the different substorm theories (Russell and McPherron, 1973; Lui, 1988; Kan and Akasofu, 1989). Under normal geomagnetic conditions the current sheet is relatively thick (Fairfield et al., 1981), but under substorm conditions it can become very thin (McPherron et al., 1987). This thickness might be controlled by either interplanetary conditions or by the substorm activity itself (Van Hoven et al., 1987; Wiegelmann and Schindler, 1995). But a quantitative determination of the temporal evolution of the current sheet thickness is difficult. In this paper we present a case study based on the observations of ISEE 3 in the solar wind, IMS ground magnetometers at the nightside and ISEE 1 , ISEE 2 and IMP 8 in the magnetotail current sheet. We concisely introduce the conditions in the solar wind, in the near and mid-tail, and on the ground. Then we use this rare but ideal condition for calculation of the current sheet thickness and the analysis of the current sheet structure.

\section{GLOBAL PERSPECTIVE}

\section{Spacecraft Positions and Magnetopause Configurations}

On April 22, 1979 from 0840 to 1018 UT, ISEE 1 and ISEE 2 stayed in the tail current sheet at about 17 Re, crossing the current sheet center several times while the initially northward IMF Bz turned Southward under conditions of constant solar wind velocity and dynamic pressure. In this interval, ISEE-3 
monitored the solar wind $206 \mathrm{Re}$ upstream and 82 Re-to the dawn side of the Earth. IMP 8 was also located in the tail at about $25 \mathrm{Re}$ and $6 \mathrm{Re}$ above the expected position of the current sheet, and 16 Re to dawn side of the Earth. Figure 1 gives the calculated magnetopause and current sheet configurations corresponding to the northward IMF condition and dipole tilt angle of the Earth at $6.2^{\circ}$ toward the sun (Petrinec and Russell, 1995; Hammond et al., 1994). Over the event period ISEE 1 and 2 are expected to slowly cross the current sheet in the center of the tail from the north to south lobe and IMP 8 to stay firmly in the northern lobe. But we will see the latter spacecraft does not, implying a significant twist of the tail current sheet.

\section{Solar Wind and Geomagnetic Conditions}

Solar wind conditions are shown in Figure 2. The time between the two dashed lines is the period corresponding to the ground event duration. The time shown on the top of Figure 2 is the universal time on the Earth. If we assume a solar wind flow propagates along the GSM $X$ axis with a speed $V s w=450 \mathrm{~km} / \mathrm{s}$, then it would arrive at the nose of the magnetosphere after about 46 minutes. For the whole duration of Figure 2, the dynamic pressure $\rho v^{2}$ remained about $3.5 \mathrm{nPa}$. The interval from 0840 to 1018 UT is in the recovery stage of a moderately strong storm, and in the middle of a series of auroral electrojet activation with $\mathrm{AE}$ index increases from 300 to $600 \mathrm{nT}$.
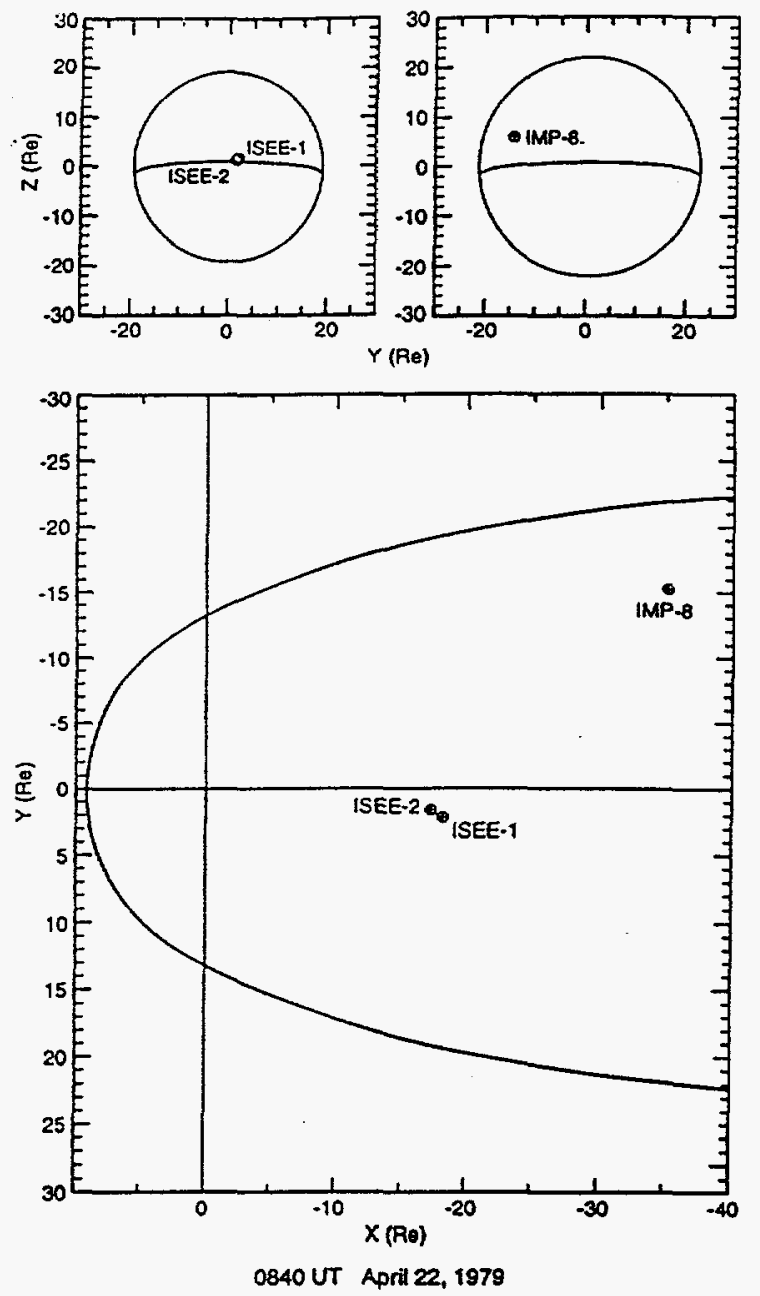

Fig. 1. Location of ISEE 1 and 2 and IMP 8 during the observations reported herein. The top panel shows the projections of the positions in the GSM YZ plane. The tail boundary and the current-sheet location are those expected from statistical models under the observed solar wind conditions and tilt of the dipole.

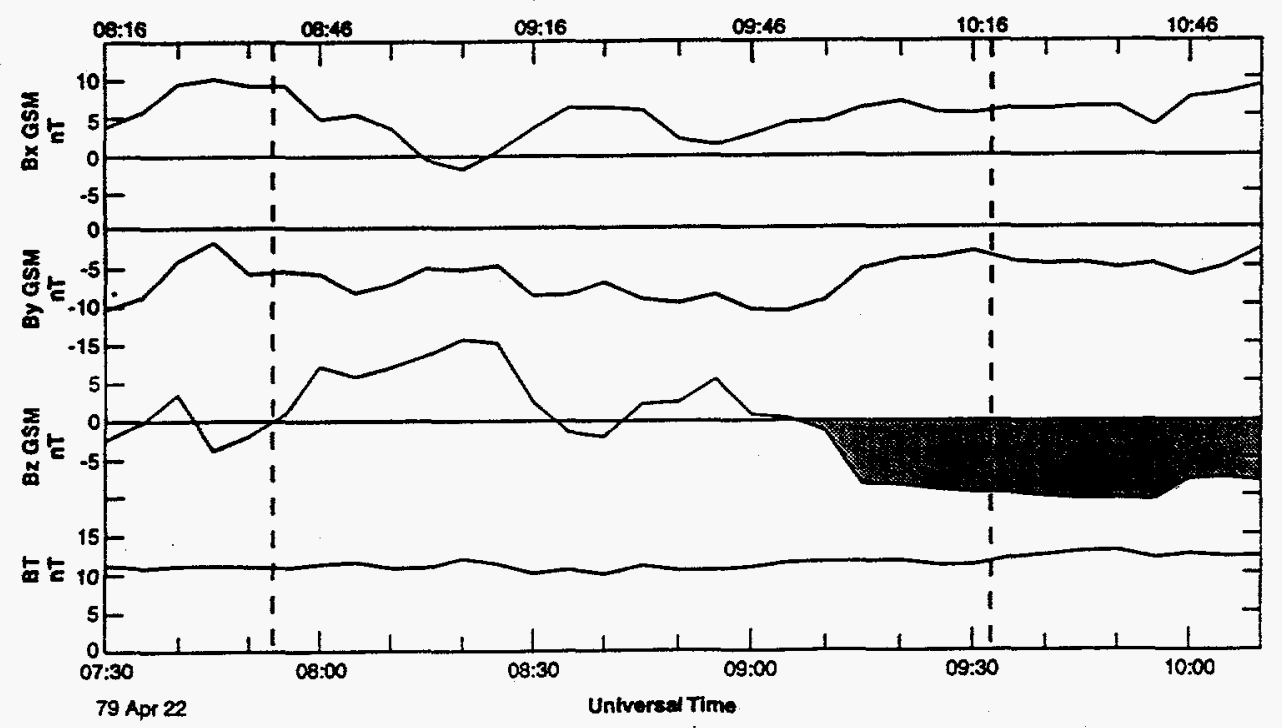

Fig. 2. The interplanetary magnetic field in GSM coordinates as observed upstream by ISEE 3 . The black shading denotes the period of strong southward IMF. 
- A strong westward electrojet with an onset at about 0953 UT is detected by the ground magnetometers as shown by Figure 3. The vertical line drawn at 0953 UT in this figure is the onset time of the southward turning of the magnetic field seen by ISEE 1 and 2 at $17 \mathrm{Re}$ in the tail. From College to Whiteshell the electrojet is very strong but at Ottawa and Saint John's it is weak, perhaps due to those stations being far from the center of the electrojet.
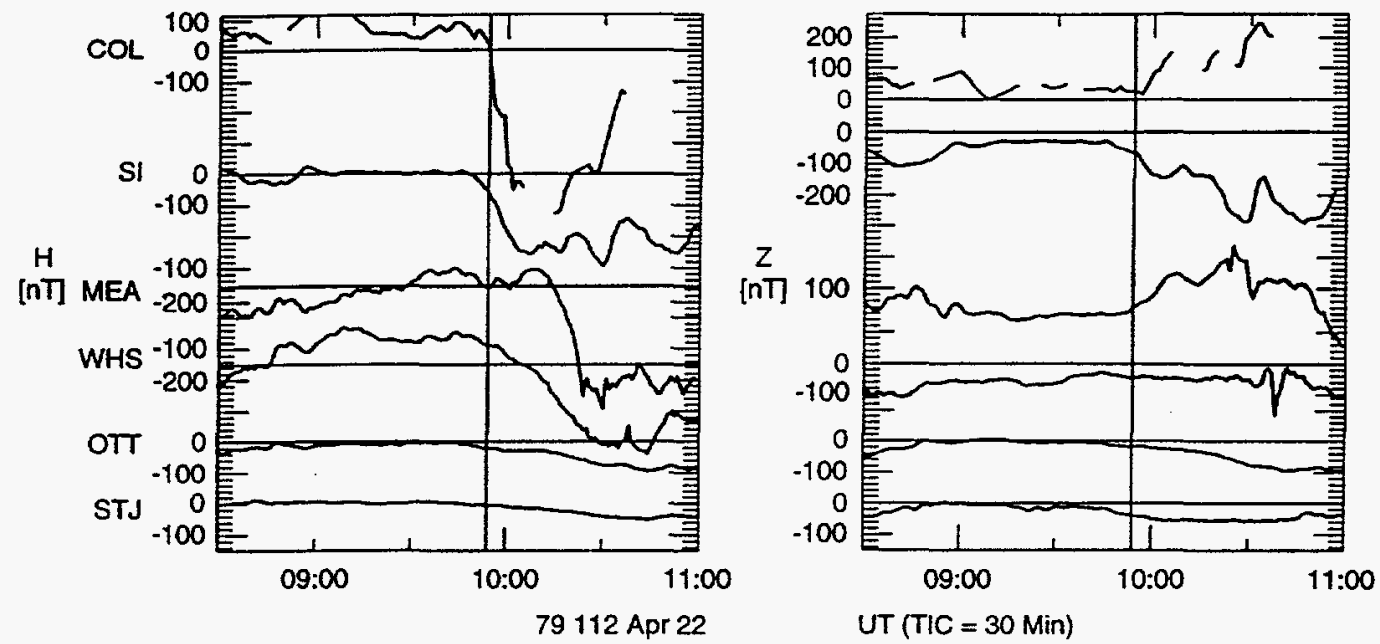

Fig. 3. Ground-based measurements of the $H$ component of the magnetic field (left) and $Z$ component of the magnetic field (right) at selected stations at high latitudes near midnight.

\section{Geomagnetic and Plasma Variations in the Tail}

The magnetic field and plasma observed by ISEE 1,2 and IMP 8 are shown in Figures 4a and 4b respectively. An earthward propagating dipolarization of the magnetic field occurred at 0847 UT. Before 0920 UT the ISEE pair remained at the center of the current sheet, so that the total pressure is mainly due to the thermal pressure which is shown by the thin line in the bottom panel of Figure $4 \mathrm{~b}$. A rapid southward turning of the tail magnetic field occurred at 0953 UT corresponding to the expected arrival time of the IMF Bz southward turning seen at ISEE 3 at 0906 UT. This apparent reconnection event then appeared to move down tail, encountering first ISEE 2 and then ISEE 1. Another very significant phenomena occurred during the northward IMF conditions. IMP 8 entered the southern lobe at 0846 UT and remained there about half an hour. This implies that the tail current sheet is twisted significantly under these IMF Bz and By conditions. This twist is in the same direction as predicted by Cowley (1981).

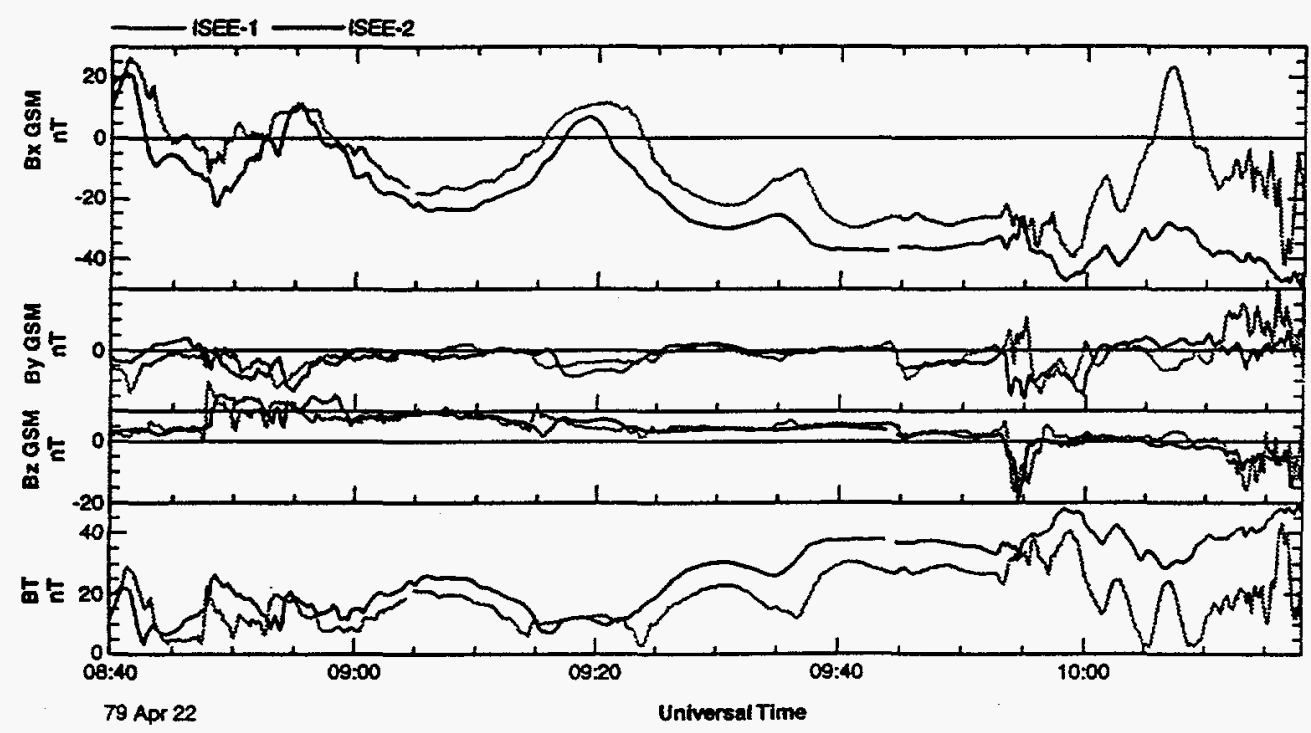

Fig. 4a. The magnetic field at ISEE 1 and 2 from 0840 to 1018 UT on April 22, 1979. The GSM coordinate system is used. 


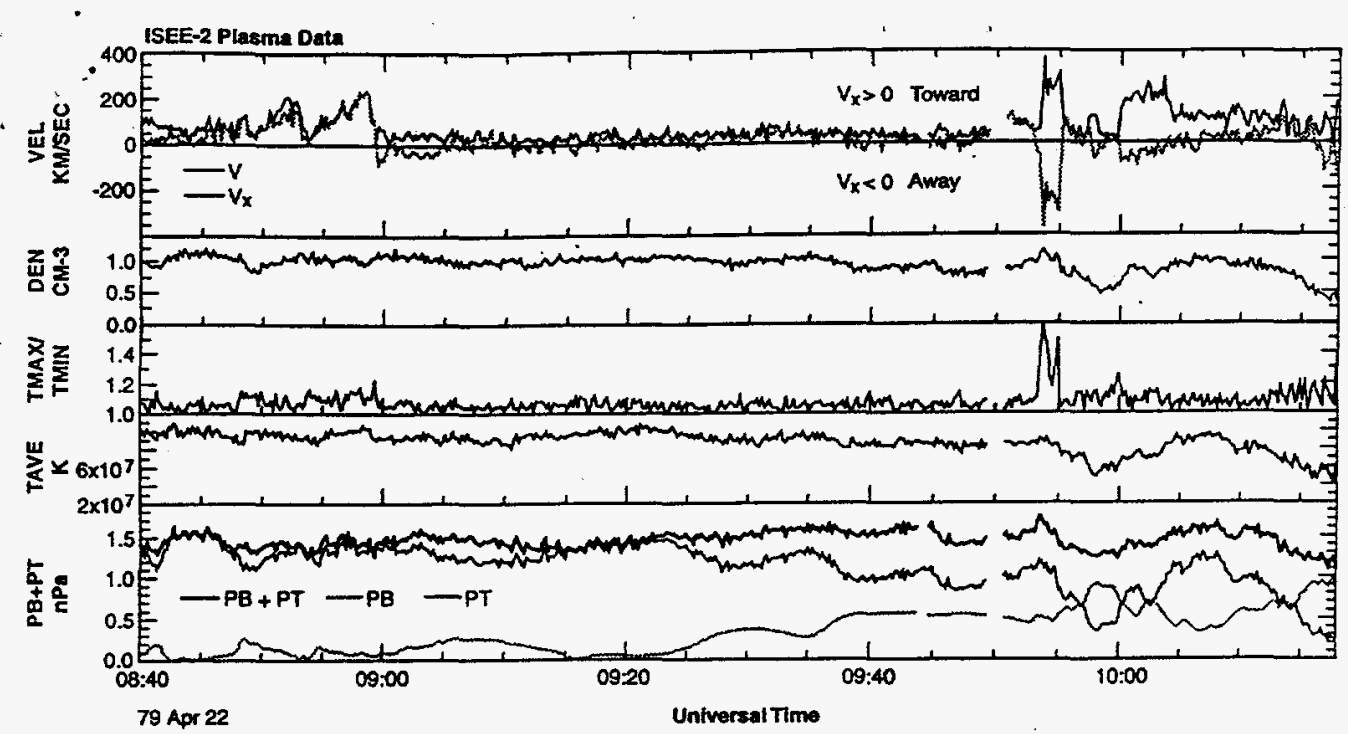

Fig: 4b. The plasma conditions at ISEE 2 from 0840 to 1018 UT on April 22, 1979. From top to bottom this figure shows the plasma velocity toward and away from the Earth; the number density; the ratio of the maximum to minimum ion temperature in one spin of the spacecraft, the average ion temperature and the plasma thermal and magnetic pressures, and their sum.

\section{THE HARRIS CURRENT SHEET STRUCTURE}

The Harris model is a simple analytical description of a one-dimensional current sheet model and is self-consistent using either MHD or kinetic theory. In a Harris current sheet, the magnetic field is given by

$$
\mathrm{Bx}=\mathrm{B}_{\mathrm{o}} \tanh (\mathrm{z} / \mathrm{h})
$$

where $B_{0}$ is the lobe field, $z$ is the distance between the observation point and the current sheet center, $h$ is the current sheet half thickness. With observations from two vertically spaced spacecraft both in the current sheet, formula (1) can be rewritten

$$
\mathrm{h}=2 \Delta \mathrm{z} / \ln \left[\left(\mathrm{B}_{\mathrm{o}}{ }^{2}+\mathrm{B}_{\mathrm{o}} \Delta \mathrm{B}_{\mathrm{x}}-\mathrm{B}_{\mathrm{x} 1} \mathrm{~B}_{\mathrm{x} 2}\right) /\left(\mathrm{B}_{\mathrm{o}}{ }^{2}-\mathrm{B}_{\mathrm{o}} \Delta \mathrm{B}_{\mathrm{x}}-\mathrm{B}_{\mathrm{x} 1} \mathrm{~B}_{\mathrm{x} 2}\right)\right]
$$

where $\Delta \mathrm{z}=\mathrm{z} 1-\mathrm{z} 2, \mathrm{z} 1$ and $\mathrm{z} 2$ are the positions of the two spacecraft in the $\mathrm{Z}$ direction of the GSM coordinates, $\triangle \mathrm{Bx}=\mathrm{Bx} 1-\mathrm{Bx} 2, \mathrm{Bx} 1$ and $\mathrm{Bx} 2$ are the $\mathrm{Bx}$ components observed by the two spacecraft separately. The lobe field $B_{0}$ can be calculated under conditions of constant total pressure through the lobe. When we use a coefficient of 2.15 to recalibrate the plasma density to get a constant total pressure through the plasma sheet from one lobe to the other, the lobe field $B_{0}=52.6 \mathrm{nT}$. The calculated current sheet center position $z_{o}$ in GSM and the half thickness are given in Figure 5. Up and down motion of the current sheet is very clear in the top panel before 0938 UT. Over the whole event the current sheet center was mainly above the equatorial plane, at an average height of about $1.1 \mathrm{Re}$. As shown in the bottom panel of Figure 5, before 0920 UT the average thickness is about $2.5 \mathrm{Re}$ but it varied very much.

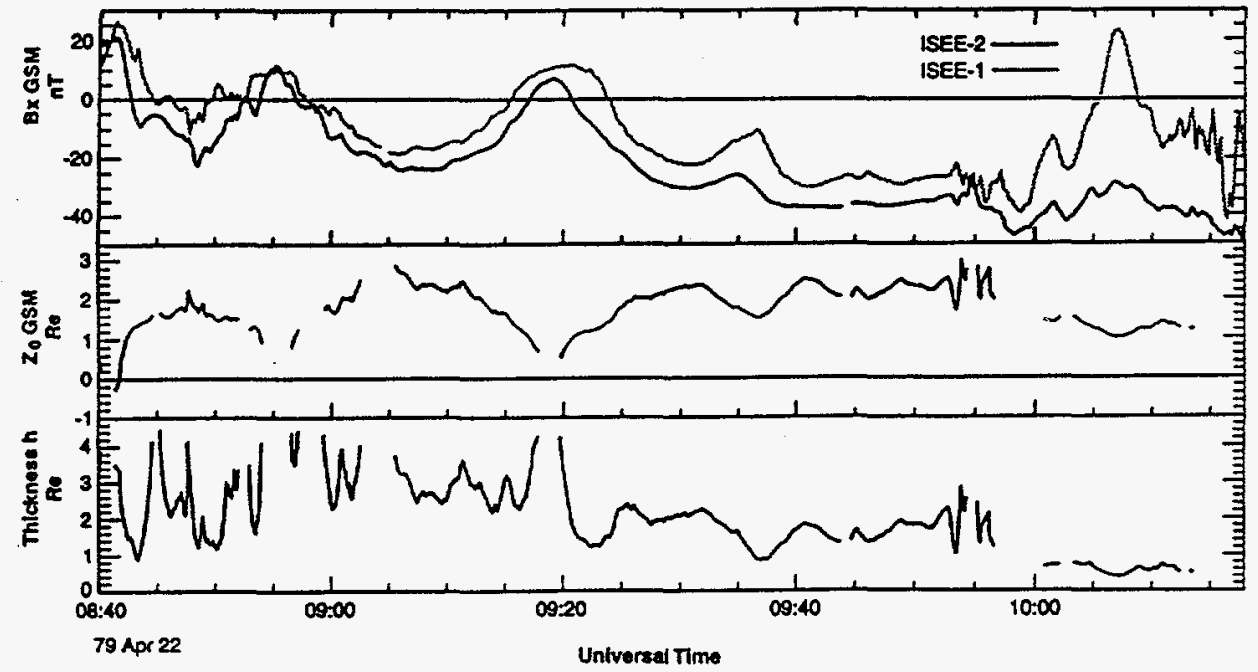

Fig. 5. The magnetic field and inferred parameters from the Harris current sheet model. The top panel shows the magnetic field components in the GSM $X$ direction. The middle panel shows the distance of the spacecraft from the center of the current sheet. The bottom panel shows the computed thickness of the current sheet. 
Between 0920 to 1000 UT the thickness was relatively smooth and the average value is about $1.5 \mathrm{Re}$, but osicillated near the time of the reconnection event. After 1000 UT the current sheet monotonically thinned to an average thickness of $0.5 \mathrm{Re}$.

From the Harris current sheet model we also can analyze the structure of the plasma sheet along the vertical direction. We assume the current sheet magnetic structure is antisymmetric around the current sheet center and that the plasma properties as observed by ISEE 2 are symmetric about $z_{o}$, so we reflect the plasma data about $z_{\mathrm{o}}$. Figure 6 shows the plasma distribution in the vertical direction. In Figure 6 the plasma density and average temperature are high at the center and low at the edges, which is very close to a Gaussian distribution. In Figure $6 \mathrm{c}$ the difference between the observed and the theoretical thermal pressure might be because the error in the observed Tperp and the limited detector range. Thus, while not a perfect match to the structure of the magnetotail current sheet the Harris model gives a good zeroth order approximation to it.
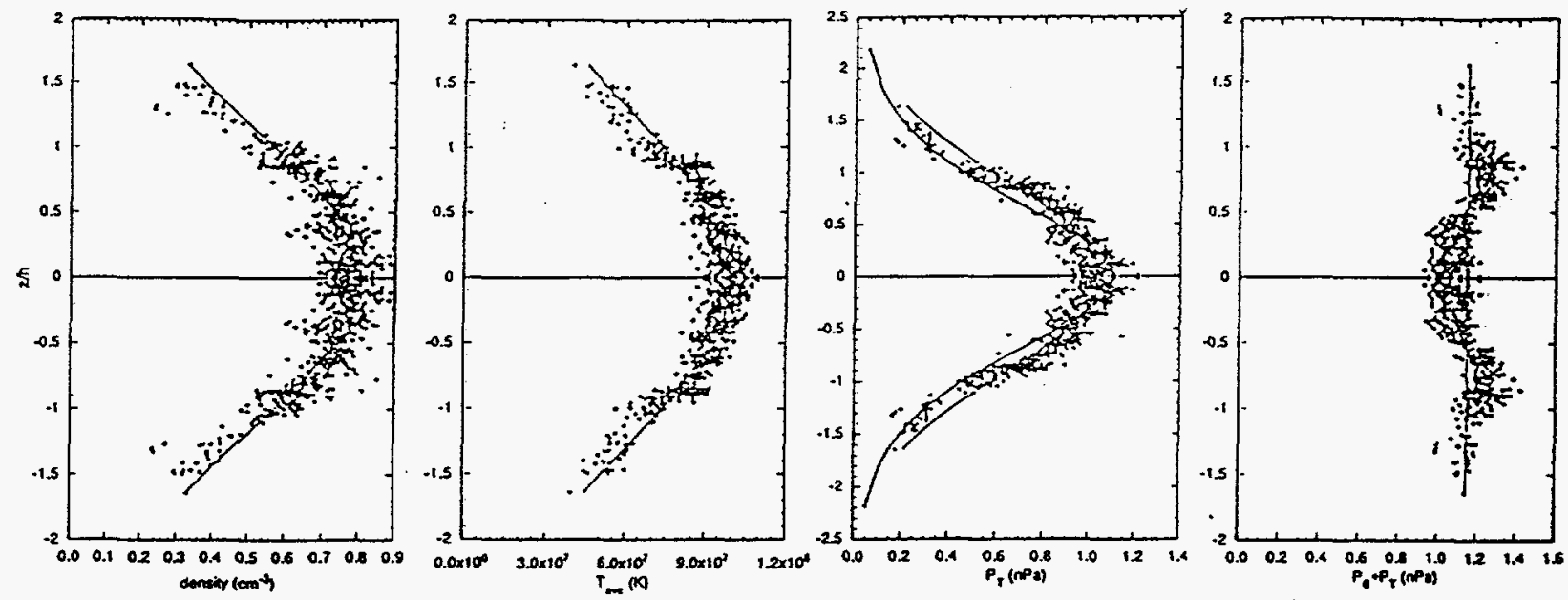

Fig. 6. The plasma parameters plotted as a function of the normalized distance from the current-sheet center using the Harris current-sheet model. The left-hand panel gives the plasma number density, the next panel the spin average ion temperature, the next panel the thermal pressure and the last panel the sum of the plasma thermal and magnetic pressures.

\section{REFERENCES}

Cowley, S. W. H., Magnetospheric asymmetries associated with the Y-component of the IMF, Planet. Space Sci., 29, 79-96, 1981.

Fairfield, D. H., R. P. Lepping, E. W. Hones, Jr., S. J. Bame, and J. R. Asbridge, Simultaneous Measurements of Magnetotail Dynamics by IMP Spacecraft, J. Geophys. Res., 86, 1396(1981).

Hammond, C. M., M. G. Kivelson, and R. J. Walker, Imaging the Effect of Dipole Tilt on Magnetotail Boundaries, J. Geophys. Res., 99, 6079 (1994).

Kan, J., and S.-I. Akasofu, Electrodynamics of Solar Wind-Magnetosphere Ionosphere Interactions, IEEE Trans. Plasma Science, 17, 83(1989)

Lui, A. T. Y., R. E. Lopez, S. M. Krimigis, R. W. McEntire, L. J. Zanetti, and T. A. Potemra, A Case Study of Magnetotail Current Sheet Disruption and Diversion, Geophys. Res. Lett., 15, 721(1988).

McPherron, R. L., A. Nishida, and C. T. Russell, Is Near-Earth Current Sheet Thinning the Cause of Auroral Substorm Onset?, in Quantitative Modeling of Magnetosphere-Ionosphere Coupling Processes, pp. 252-257, Kyoto Sangyo Univ., Kyoto, Japan(1987).

Petrinec, S. M., and C. T. Russell, Near-Earth Magnetotail Shape and Size as Determined from the Magnetopause Flaring Angle, J. Geophys. Res., 101,137(1995).

Russell, C. T., and R. L. McPherron, The Magnetotail and Substorms, Space Sci. Rev., 15, 205(1973). Van Hoven, G., L. Sparks, and D. D. Schnack, Nonlinear Radiative Condensation in a Sheared Magnetic Field, Ap. J., 317, L91 (1987).

Wiegelmann, T., and K. Schindler, Formation of Thin Current Sheets in a Quasistatic Magnetotail Model, Geophys. Res. Lett., 22,2057 (1995). 